\title{
Spatial Pattern of Nerve Differentiation in Hydra Is Due to a Pattern of Nerve Commitment
}

\author{
G. Venugopal and Charles N. David \\ Department of Molecular Biology, Albert Einstein College of Medicine, Bromx, New York 10461 \\ Received June 9, 1980; accepted in revised form August 17, 1980
}

\begin{abstract}
The pattern of nerve differentiation along the body column of Hydra was investigated. Nerve precursors in late $\mathrm{S}$ phase were labeled with $\left.{ }^{3} \mathrm{H}\right]$ thymidine and their distribution compared with that of newly differentiated nerves. The two distributions were found to be the same. Based on independent evidence that nerve commitment occurs in midto late S phase (G. Venugopal and C. David, 1981, Develop. Biol. 83, 361-365) it was concluded that the pattern of nerve differentiation along the body column of Hydra is due to differences in nerve commitment in different body regions. Furthermore, the level of nerve commitment in head and foot tissue is sufficiently high to deplete stem cells in these regions as is observed.
\end{abstract}

\section{INTRODUCTION}

Interstitial stem cells in Hydra continuously give rise to differentiated nerves and nematocytes (see Bode and David (1978) for review). Averaged over the whole animal, $30 \%$ of stem cell daughters enter the nematocyte pathway, $10 \%$ enter the nerve pathway, and $60 \%$ remain stem cells in each stem cell generation (David and Gierer, 1974). Stem cells are distributed uniformly throughout the gastric region but are notably depleted in the head and foot regions and immediately adjacent tissue (David and Plotnick, 1980). Nematocyte differentiation parallels the stem cell distribution and thus is localized in the gastric region (David and Challoner, 1974). By comparison, nerve differentiation is distributed rather uniformly along the body column (David and Gierer, 1974). In particular, extensive nerve differentiation occurs in both the head and foot regions despite the dramatically lower concentration of stem cells in these regions.

There appear to be two simple explanations for the high level of nerve differentiation in head and foot tissue: (1) the fraction of stem cells committed to nerve differentiation is higher in head and foot tissue than in gastric tissue thus compensating for the lower concentration of stem cells in these regions; (2) committed nerve precursors migrate from the body column into head and foot regions thereby increasing the rate of nerve differentiation in these regions over that expected from the low concentration of stem cells. Indeed, there are several reports in the literature of interstitial cell migration into heads and regenerating tips (Tardent and Morgenthaler, 1966; Herlands and Bode, 1974; Yaross and Bode, 1978).
These two possibilities can be distinguished by comparing the distribution of nerve precursors with the distribution of newly differentiated nerve cells. If migration occurs we expect these two distributions to differ; if enhanced nerve commitment is responsible for the high levels of nerve differentiation in head and foot, we expect nerve precursors and newly differentiated nerves to be distributed similarly.

Nerve precursors can be labeled with $\left[{ }^{3} \mathrm{H}\right]$ thymidine 18-30 hr prior to terminal differentiation (David and Gierer, 1974). We have, therefore, compared the distribution of labeled nerve precursors with the distribution of newly differentiated nerves. The results indicate no detectable redistribution of nerve precursors between late $S$ phase and terminal differentiation. Since independent evidence (Berking, 1979; Venugopal and David, $1981 \mathrm{~b}$ ) indicates that nerve commitment occurs in midto late $S$ phase, we conclude that the pattern of nerve differentiation in Hydra is due to an increase in the fraction of stem cells committed to nerve differentiation in head and foot tissue compared to gastric tissue.

\section{MATERIAL AND METHODS}

Hydra were cultured at $18-19^{\circ} \mathrm{C}$ in $10^{-3} \mathrm{M} \mathrm{CaCl}_{2}, 10^{-3}$ $M \mathrm{NaHCO}_{3}$, and $10^{-5} M$ EDTA. Cultures were fed daily with Artemia nauplii and washed $6 \mathrm{hr}$ later. Experimental animals were maintained in closed petri dishes at $20-21^{\circ} \mathrm{C}$.

Budless Hydra selected from the culture $24 \mathrm{hr}$ after the last feeding were used in all experiments. The animals contained about 8000 epithelial cells and about 40,000 total cells. Sizes of individual sections (expressed 

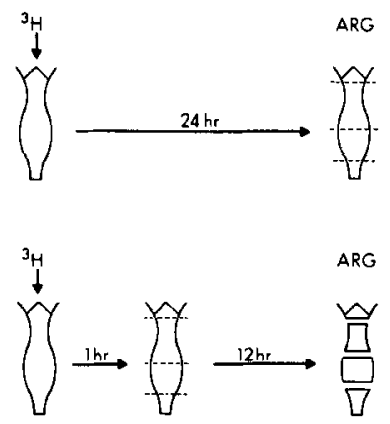

FIG. 1. Schematic representation of experimental protocol. See text for details. Top, control Hydra; bottom, sectioned Hydra.

in terms of epithelial cells) are given in the figure legends.

Counting nerves, stem cells, and epithelial cells in tissue sections. Tissue maceration (David, 1973) was used to identify and count individual cell types. Maceration dissociates Hydra tissue into single cells and small clusters of interstitial cells. Cells are fixed and retain their in vivo morphology in macerations; thus, they are easily counted by phase contrast microscopy.

The number of epithelial cells is a convenient measure of epithelial surface area or piece size. Thus we normalize all cell numbers to the number of epithelial cells in a sample in order to make comparison between experiments.

The detailed technique for preparing macerations and counting cells is described elsewhere (Sproull and David, 1979a; Venugopal and David, 1981a).

Labeling with $\left[{ }^{3} \mathrm{H}\right]$ thymidine. Hydra were labeled with $\left[{ }^{3} \mathrm{H}\right]$ thymidine $(100 \mu \mathrm{Ci} / \mathrm{ml} ; 30 \mathrm{Ci} / \mathrm{mmole})$ by injecting $0.1 \mu \mathrm{l}$ of isotope solution into the gastric cavity (David and Campbell, 1972). Under these conditions, all the isotope is taken up within about $45 \mathrm{~min}$.

To score labeled nerve cells, tissue samples were macerated, dried on slides, and autoradiographed using Kodak AR10 stripping film.

\section{RESULTS AND DISCUSSION}

\section{Distribution of Nerve Precursors and Newly Differentiated Nerves in Hydra}

The experimental protocol is outlined schematically in Fig. 1. To determine the distribution of newly differentiated nerves, control Hydra were pulse-labeled with $\left[{ }^{3} \mathrm{H}\right]$ thymidine and incubated for $24 \mathrm{hr}$ to permit differentiation of labeled nerves. The Hydra were then cut into sections as shown, macerated, and scored for labeled nerves by autoradiography. To determine the distribution of nerve precursors, Hydra were pulse-labeled as above and then cut into sections $1 \mathrm{hr}$ later to prevent redistribution of the labeled precursors. The sections were then incubated for $12 \mathrm{hr}$ to permit dif- ferentiation of labeled nerves, macerated and scored, by autoradiography.

Nerve differentiation continues normally in isolated pieces of tissue (Venugopal and David, 1981a). However, the time lag from the end of $S$ phase to nerve differentiation is shortened from about $18 \mathrm{hr}$ in control $\mathrm{Hy}$ dra to about $9 \mathrm{hr}$ in isolated pieces (Venugopal and David, 1981b). Thus, in the protocol outlined in Fig. 1, nerve precursors labeled during the last $6 \mathrm{hr}$ of $\mathrm{S}$ phase are scored in control Hydra; precursors labeled during the last $4 \mathrm{hr}$ of S phase are scored in sectioned Hydra. Isolated pieces can not be incubated longer since, after $12 \mathrm{hr}$, the differentiation of newly committed nerves induced by head and foot regeneration of the isolate begins (Venugopal and David, 1981a).

Results of two independent experiments are shown in Figs. 2A and 3A. Animals were cut into four or five sections as shown, processed according to the protocol in Fig. 1, and scored for labeled nerves cells $\left(\mathrm{Ne}^{*}\right)$ and epithelial cells (Epi). The ratio of Ne*/Epi is plotted along the body column. We have plotted the results from control Hydra and sectioned Hydra on different ordinates in order to compensate for the larger number of labeled nerves in control Hydra (due to longer incubation time). The results indicate no difference in the distribution of $\mathrm{Ne}^{*} /$ Epi between control Hydra and sec-

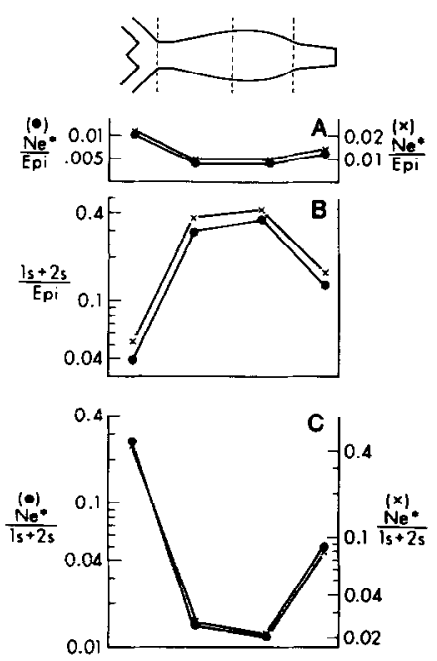

FIG. 2. Distribution of labeled nerves and stem cells along the body column. Control Hydra (x) or sectioned $H y d r a(\bullet)$ were pulse-labeled with $\left[{ }^{3} \mathrm{H}\right]$ thymidine, incubated, and sampled as shown in Fig. 1 . The numbers of labeled nerves $\left(\mathrm{Ne}^{*}\right)$ and $1 \mathrm{~s}+2 \mathrm{~s}$ were normalized to the number of epithelial cells (Epi) in each section. Abscissa represents position along the body column in units of epithelial cells. It corresponds roughly to the Hydra outlined at the top. Average size of each piece starting from the head is: $1900,2600,2600$, and 1000 epithelial cells. Each experimental value is positioned in the center of the piece on the abscissa. (A) $\mathrm{Ne}^{*} / \mathrm{Fpi}$, results of control and sectioned $\boldsymbol{H y d r a}$ are plotted on different ordinates. (B) $1 \mathrm{~s}+2 \mathrm{~s} / \mathrm{Epi}$. (C) $\mathrm{Ne}^{*} / 1 \mathrm{~s}+2 \mathrm{~s}$, results of control and sectioned $H y d r a$ are plotted on different ordinates. 


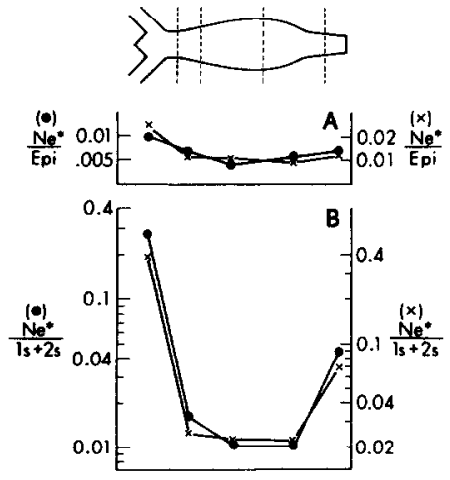

FIG. 3. Distribution of labeled nerves $\left(\mathrm{Ne}^{*}\right)$ and the ratio of $\mathrm{Ne}^{*} /$ $1 s+2 s$ along the body column. Control Hydra $(X)$ and sectioned Hydra (๑) were labeled and sampled as in Fig. 2. Average size of each piece starting from the head is: $1800,900,2000,2000$, and 900 epithelial cells. (A) $\mathrm{Ne}^{*} /$ Epi. (B) $\mathrm{Ne}^{*} / 1 \mathrm{~s}+2 \mathrm{~s}$; note different ordinates for control and sectioned Hydra.

tioned Hydra. Thus, late $\mathrm{S}$ phase nerve precursors are distributed along the body column in a pattern which is identical to that of newly differentiated nerve cells. We conclude, therefore, that no redistribution of nerve precursors occurs after late $S$ phase. If any redistribution occurs, it must be complete by mid-S phase of the precursor cell cycle.

It is important to note the limitations of our data in view of earlier reports of cell migration in Hydra (Tardent and Morgenthaler, 1966; Herlands and Bode, 1974; Yaross and Bode, 1978). Our experiment is not sensitive enough to detect low levels of migration. For example, if $10-20 \%$ of the $\mathrm{Ne}^{*}$ scored in head and foot tissue were due to migration of nerve precursors from the body column, it would probably go undetected in our experiment against the large background of $\mathrm{Ne}^{*}$ already present in head and foot tissue. Furthermore, our experiment only scores migration over a short time interval $(12 \mathrm{hr})$ compared to the longer time intervals used in earlier studies. Thus, our results are not in disagreement with the interstitial cell migration that has been reported by others. Rather they suggest that most of that migration is probably due to stem cells rather than committed precursors (see below). Our results do, however, indicate that migration of committed precursors does not contribute significantly to the observed pattern of nerve differentiation in Hydra.

\section{The Pattern of Nerve Commitment}

In order to use the above results to determine whether the pattern of nerve differentiation along the body column of Hydra is due to a pattern of nerve commitment or to precursor migration, we need to know the timing of the commitment event in the precursor cell cycle. If nerve commitment occurs before mid-S phase, then redistribution of committed cells could contribute to the observed pattern of $\mathrm{Ne}^{*} / \mathrm{ls}+2 \mathrm{~s}$. However, if commitment occurs in mid-S phase or later, then the observed pattern of $\mathrm{Ne}^{*} / 1 \mathrm{~s}+2 \mathrm{~s}$ can only be due to differences in the level of nerve commitment in different regions of the body column.

Three independent lines of evidence indicate that nerve commitment occurs in mid-S phase or later. (1) Regeneration induces extensive nerve differentiation starting $12 \mathrm{hr}$ after cutting (Bode et al., 1973; Venugopal and David, 1981a). Since this differentiation is induced by regeneration, nerve commitment cannot precede nerve differentiation by more than $12 \mathrm{hr}$. Hence nerve commitment can occur no earlier than late $S$ phase of the precursor. (2) Berking (1979) has shown that nerve differentiation is affected by an inhibitory morphogen before but not after mid-S phase of the precursor cell cycle. After mid-S phase cells appear "committed" to nerve differentiation. (3) Finally, Venugopal and David (1981b) have used an assay for self differentiation to show that differentiation of nerve precursors becomes independent of exogenous signals, i.e., committed, at mid-S phase. Taken together these results localize nerve commitment to a point in mid- to late $S$ phase of the precursor cell cycle. Thus, the nerve precursors whose distribution we measured in Figs. 2A and 3A were newly committed cells. The fact that these cells have the same distribution as newly differentiated nerves rules out any major contribution of cell migration to the pattern of nerve differentiation. The pattern must, therefore, be due to strong differences in the level of nerve commitment in different regions of the body column.

The fraction of stem cells committed to nerve differentiation can be estimated from the ratio of labeled nerves to stem cells (estimated as $1 \mathrm{~s}+2 \mathrm{~s}$ ) (Sproull and David, 1979b). Figure 2B shows the distribution of $1 s+2 s$ along the body column. The results are similar to previous observations (Bode et al., 1973; David and Plotnick, 1980). Figure 2C shows the ratio of $\mathrm{Ne}^{*} / 1 \mathrm{~s}+2 \mathrm{~s}$ calculated from the results in Figs. 2A and B. The ratio is strongly patterned: in head and foot tissue the ratio is 10 - to 20 -fold higher than in gastric tissue. Because the gastric region was not further subdivided in the experiment shown in Fig. 2, it is possible that the drop in $\mathrm{Ne}^{*} / 1 \mathrm{~s}+2 \mathrm{~s}$ is not as steep as the results in Fig. 2C indicate. To test this we examined, in a second experiment, a small piece of tissue at the distal end of the gastric region next to the head. The results in Fig. 3B indicate that, also in this case, the drop in $\mathrm{Ne}^{*} / 1 \mathrm{~s}+2 \mathrm{~s}$ is almost 15-fold. Thus the transition from a low to high rate of nerve commitment appears to occur over a very short distance.

From the $\mathrm{Ne}^{*} / 1 \mathrm{~s}+2 \mathrm{~s}$ ratio in Figs. $2 \mathrm{C}$ and $3 \mathrm{~B}$ it is 
possible to estimate that the fraction of stem cells undergoing nerve commitment in head and foot regions is $>0.7$ compared to $<0.05$ in the gastric region (Sproull and David, 1979b). Under these conditions the stem cell population in head and foot tissue declines with every cell generation. Thus, nerve commitment localized in head and foot tissue may be responsible for the observed depletion of stem cells in these regions (David and Plotnick, 1980). The small stem cell population which continues to exist in the head and foot is probably carried into these regions by slow distal and proximal movement of tissue from the gastric region (Campbell, 1967).

The pattern of nerve commitment is qualitatively similar to the pattern of morphogenetic potential in Hydra. Nerve commitment is high in head and foot regions which are morphogenetically dominant and low in gastric tissue which is morphogenetically neutral. This parallel also extends to changes in morphogenetic potential during head regeneration (Venugopal and David, 1981a). Thus it appears likely that nerve commitment is controlled by signals which are closely related to the signals which control morphogenesis in Hydra.

The authors thank Dr. H. K. MacWilliams for many helpful discussions and critical review of the manuscript. This research was supported by grants from the NIH (GM 11301) and the NSF (7725426). C.N.D. is recipient of a Career Development Award (FRA-132) from the American Cancer Society.

\section{REFERENCES}

BERKING, S. (1979). Control of nerve cell formation from multipotent stem cells in Hydra. J. Cell Sci. 40, 193-205.

Bode, H., Berking, S., David, C. N., Gierer, A., Schaller, H., and TRENKNER, E. (1973). Quantitative analysis of cell types during growth and morphogenesis in Hydra. Wilhelm Roux Arch. Entwicklungsmech. Organismen 171, 269-285.
BoDE, H., and DAvID, C. N. (1978). Regulation of a multipotent stem cell, the interstitial cell of Hydra. Progr. Biophys. Mol. Biol. 33, 189-206.

CAMPBELL, R. D. (1967). Tissue dynamics of steady state growth in Hydra littoralis. II. Patterns of tissue movement. J. Morphol. 121, 19-28.

DAviD, C. N. (1973). A quantitative method for maceration of $H y d r a$ tissue. Wilhelm Roux Arch. Entwicklungsmech. Organismen 171, 259-268.

DAviD, C. N., and CAMPBELL, R. (1972). Cell cycle kinetics and development of Hydra attenuata. I. Epithelial cells. J. Cell Sci, 11, $557-568$.

David, C. N., and Challoner, D. (1974). Distribution of interstitial cells and differentiating nematocytes in nests in Hydra attenuata. Amer. Zool. 14, 537-542.

DAviD, C. N., and GIERER, A. (1974). Cell eycle kinetics and development of Hydra attenuata. III. Nerve and nematocyte differentiation. J. Cell Sci. 16, 359-375.

DA VID, C. N., and PLOTNICK, I. (1980). Distribution of interstitial stem cells in Hydra. Develop. Biol. 76, 175-184.

HERLANDS, R., and BODE, H. (1974). Oriented migration of interstitial cells and nematocytes in Hydra attenuata. Wilhelm Roux Arch. Entwicklungsmech. Organismen 176, 67-88.

Sproull, F., and DAVID, C. N. (1979a). Stem cell growth and differentiation in Hydra attenuata. I. Regulation of the self-renewal probability in multiclone aggregates. J. Cell Sci. 38, 155-169.

Sproull, F., and DaVID, C. N. (1979b). Stem cell growth and differentiation in Hydra attenuata. II. Regulation of nerve and nematocyte differentiation in multiclone aggregates. J. Cell Sci. 38, 171179 .

TARDENT, P., and MORGENTHALER, U. (1966). Autoradiographische Untersuchungen zum problem der Zellwanderungen bei Hydra attenuata (Pall.). Rev. Suisse Zool. 73, 468-480.

Venugopal, G., and DAVID, C. N. (1981a). Nerve commitment in Hydra attenuata. I. Role of morphogenetic signals. Develop. Biol. 83, 353-360.

VENUGoPAL, G., and DA VIn, C. N. (1981b). Nerve commitment in $\mathrm{Hy}$ dra attenuata. II. Localization of commitment in $\mathrm{S}$ phase. Develop. Biol. 83, 361-365.

YAROSS, M., and BoDE, H. (1978). Regulation of interstitial cell differentiation in Hydra attenuata. IV. Nerve cell commitment in head regeneration is position-dependent. J. Cell Sci. 34, 27-38. 